\title{
REPENSANDO AS MIGRAÇÕES A PARTIR DE UM ARCABOUÇO PROCESSUAL MULTIESCALAR
}

\author{
Rethinking migrations from a multilevel transition framework
}

\author{
Marden Barbosa de Campos*
}

\begin{abstract}
Resumo. As modificações recentes nos padrões migratórios exibidos por diversas populações forçam-nos a buscar novos enfoques analíticos que possibilitem apreender teórico-conceitualmente esses processos. Acreditase que as migrações podem ser melhor compreendidas se direcionarmos nossa atenção, simultaneamente, para as transições por que passam os indivíduos, as famílias e as populações como um todo. O objetivo deste trabalho é apresentar um arcabouço conceitual que condense os aspectos teórico-explicativos da relação da migração com as transições ocorridas ao longo do ciclo de vida individual, domiciliar e populacional. Metodologicamente, busca-se integrar os pressupostos desenvolvidos por abordagens uniescalares em um mesmo arcabouço conceitual.
\end{abstract}

Palavras-chave: teorias sobre migração; abordagem multiescalar; transição demográfica.

\begin{abstract}
Recent changes in the migratory patterns exhibited by various populations ask for new analytical approaches that make it possible to grasp these processes theoretically and conceptually. It is believed that migrations can be better understood if we direct our attention simultaneously to the transitions that individuals, families and populations go through. The aim of this paper is to present a conceptual framework that condenses the theoretical-explanatory aspects of the relationship between migration and transitions that occur throughout the individual, household and population life cycle. Methodologically, we seek to integrate the assumptions developed by unique level approaches in the same conceptual framework.
\end{abstract}

Keywords: migration theories; multilevel approach; demographic transition.

\footnotetext{
Departamento de Sociologia e do Programa de Pós-graduação em Sociologia da Universidade Federal de Minas Gerais. Belo Horizonte - MG, Brasil. E-mail: mardencampos@gmail.com. Orcid: 0000-0002-7397-5453.
} 


\section{Introdução}

Conhecer a dinâmica demográfica de uma população é central para o entendimento das mudanças por que passam as sociedades atuais. Representada pelas alterações de suas características em termos de tamanho e composição, tal dinâmica caracteriza as chamadas transições populacionais contemporâneas. Além das alterações nos níveis e estruturas dos eventos vitais (nascimentos e óbitos), atualmente têm sido observadas alterações nos padrões migratórios exibidos por diversas populações, em termos de intensidade, direcionamento e composição dos fluxos de migrantes. Essas mudanças vêm provocando uma reconfiguração das relações étnicas, legais e diplomáticas entre diversas regiões do planeta, sendo um tema de extrema sensibilidade política e complexidade teórico-analítica.

As novas configurações dos fluxos populacionais e suas imbricações em mudanças sociais mais amplas forçam-nos a buscar novos enfoques analíticos que possibilitem apreender teórico-conceitualmente esses processos, assim como fomentar o desenvolvimento de novas formas de mensuração do fenômeno. Acredita-se que as migrações podem ser mais bem compreendidas se direcionarmos nossa atenção para as transições por que passam os indivíduos, as famílias e as populações como um todo, ao invés de focalizarmos as análises exclusivamente em atributos localizados em apenas um desses níveis escalares. Embora a ampliação do foco possa obscurecer particularidades do processo concentradas em determinada escala analítica, a abordagem multi-escalar mostra os diferentes pesos explicativos contidos em "outras escalas", precavendo-nos de dar um peso demasiadamente grande a aspectos que, visto por uma perspectiva ampla, não atuam isoladamente.

O objetivo deste trabalho é apresentar um arcabouço conceitual que condense os aspectos teórico-explicativos da relação da migração com as transições ocorridas ao longo do ciclo de vida individual, domiciliar e populacional, simultaneamente, em uma abordagem demográfica do fenômeno. Procura-se destacar que a natureza dinâmica do comportamento migratório decorre de aspectos localizados em diferentes níveis escalares. Procura-se, nesse sentido, apresentar uma perspectiva processual das migrações, articuladora de desenvolvimentos teóricos concentrados em aspectos explicativos restritos em termos da escala do fenômeno. Tal perspectiva leva em conta as diferentes temporalidades (por isso processual) experimentadas nas vidas individuais, familiares e históricos das populações.

Pressupõe-se que características individuais, familiares e da sociedade atuam, simultaneamente, selecionando os indivíduos entre aqueles propensos a migrar, enquanto "fixa" outra parte deles em seus locais de residência, por 
vezes durante toda a vida. Busca-se integrar os pressupostos desenvolvidos por abordagens uniescalares em um mesmo arcabouço conceitual.

A análise fragmentada do comportamento migratório, alvo de críticas por diversos estudiosos, é o tema da primeira seção, que também discute as possibilidades de reintegração de abordagens teóricas distintas. Em seguida, na segunda, terceira e quarta seções, são descritas as perspectivas de transição para indivíduos, famílias e população, separadamente, para, na seção seguinte, propor a integração dessas abordagens. A última seção, de caráter conclusivo, apresenta os desafios gerados por esse método de análise da migração.

\section{Compartimentalização das análises migratórias}

Dentre os embates metodológicos que ocorrem nas ciências sociais, um dos mais polêmicos refere-se ao locus privilegiado do "acontecimento social". Giddens e Turner (1999), na introdução do compêndio Teoria Social Hoje, assim como Alexander (1987), ao fazerem um balanço dos avanços recentes na elaboração de teorias sociais, mostram que, na maior parte das vezes, enquanto alguns autores realizam microanálises do comportamento social, outros ignoram completamente a escala individual na construção e seus marcos teórico-explicativos. Contudo, segundo os autores, nas últimas décadas houve um esforço de estudiosos de diferentes correntes de pensamento na busca por uma reconciliação entre macro e microanálise. Diversos estudiosos importantes das ciências sociais ecoam tal preocupação, lamentando a fragmentação das escalas analíticas de seus campos de estudo (Burt, 2005; Santos, 1998).

Pois o mesmo ocorre no marco das teorias desenvolvidas para explicar a ocorrência da migração. Nas palavras de Massey e colegas, esse seria um campo fortemente marcado por compartimentalização disciplinar e fragmentação teórica (Massey et alii, 1998). Tal fato prejudicaria, conforme Brettel e Hollifiel (2000) o reconhecimento de interações primordiais entre variáveis importantes do fenômeno, gerando um "canyon profundo" entre as disciplinas que estudam a migração.

A presente análise pretende gerar perspectivas para articulação de escalas dos processos para estudo da migração, não focando, contudo, na forma de interação entre agentes e estruturas, mas sim entre processos que ocorrem em diferentes níveis. Essa abordagem parte do pressuposto de que os indivíduos, à medida que envelhecem, atravessam etapas do ciclo de vida para as quais são socialmente atribuídos diferentes papéis que, por sua vez, influenciam sua propensão para migrar. Como a predisposição migratória é, empiricamente, bastante pronunciada em relação a idades específicas, fala-se de uma seletividade da migração à idade. Ao mesmo tempo, no nível 
familiar, ocorre a sobreposição das idades individuais dos moradores que, em um conjunto, determinam a composição ou estrutura domiciliar. Esta estrutura, definida como a combinação entre o número de moradores e suas idades (etapas no ciclo de vida) interfere no processo decisório da migração, levando alguns indivíduos a migrar ou a todos eles acompanharem os outros em suas migrações. Como esta estrutura é dinâmica, devido às modificações na composição dos domicílios ao longo do tempo, pode-se falar em um ciclo de vida do domicílio e, consequentemente, uma alteração no padrão migratório domiciliar. Por fim, em nível mais agregado, destacam-se as alterações experimentadas na composição da população por indivíduo com diferentes idades, no processo de dinâmica demográfica. As populações de todo o mundo têm passado por uma alteração de sua composição etária, processo que é acompanhado de uma alteração em seus padrões de deslocamento espacial.

Na Figura 1 são apresentados, de forma esquemática, os elementos que compõe a abordagem proposta.

Figura 1 - Elementos para uma abordagem multiescalar de transição

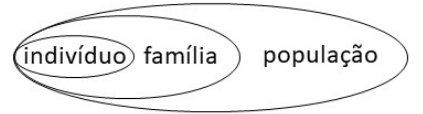

unidade de análise

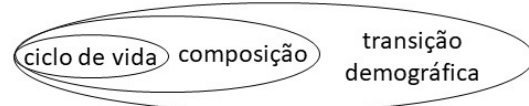

processos

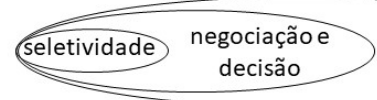

padrões de

mobilidade

influência na migração

Fonte: elaboração própria

Da mesma forma como enxergamos os indivíduos inseridos em estruturas sociais maiores, como a família ou a população, buscamos inserir o ciclo de vida individual como parte constituinte do ciclo de vida domiciliar, estando ambos incluídos no processo de transição demográfica da população. Assim, um entendimento do processo migratório deveria considerar, conjuntamente, a seletividade etária da migração, as alterações na configuração domiciliar e as mudanças no padrão migratório da população. Do mesmo modo que estas 
unidades de análise articulam-se entre si, as transições experimentadas em cada uma delas integram-se mutuamente.

As seções seguintes descrevem, de forma detalhada, a relação entre a migração e as transições experimentadas em cada uma das unidades de análise aqui consideradas.

\section{Transições e migração em diferentes escalas}

\section{O ciclo de vida individual}

Uma das principais características destacas por estudiosos da migração é sua elevada seletividade em relação a atributos individuais. Dentre estes atributos, um dos que mais afetam a probabilidade de um indivíduo migrar é a sua idade. É sabido que, à medida que envelhecem, os indivíduos atravessam etapas do ciclo da vida que influenciam sua decisão de migrar (De Jong, Gardner, 1981).

Um dos estudiosos que destacou, de forma enfática, a seletividade etária da migração foi Everet Lee quando, em 1966, propôs um modelo de análise das migrações, conhecido como "modelo push-pull". Lee argumenta que os migrantes não constituem uma amostra aleatória da população, mas sim indivíduos com características pessoais específicas que respondem de maneira diferente a estímulos e obstáculos (Lee, 1980 [1966]). O autor afirma que a "força" com que os estímulos e obstáculos à migração atuam sobre os indivíduos irá depender, em grande medida, do momento da vida em que ele se encontra, ou seja, sua "etapa do ciclo vital" (Lee, 1980 [1966], p. 102). Nesse sentido, as migrações são tratadas por ele como "rites de passages", numa clara associação à relação entre migração e as transições do ciclo de vida.

Essas regularidades observadas nos padrões etários de migração de diversas populações forneceram as bases para a elaboração de modelos etários de migração por Andrei Rogers e Luis Castro (Rogers, Castro, 1981). Os autores constataram que, embora a intensidade (nível) com que os indivíduos de cada população migravam variasse consideravelmente, o perfil (padrão) exibido pelas taxas migratórias por idade, referentes a cada população, apresentava uma persistente regularidade (Gráfico 1). 


\section{Gráfico 1 - Modelo etário de migração}

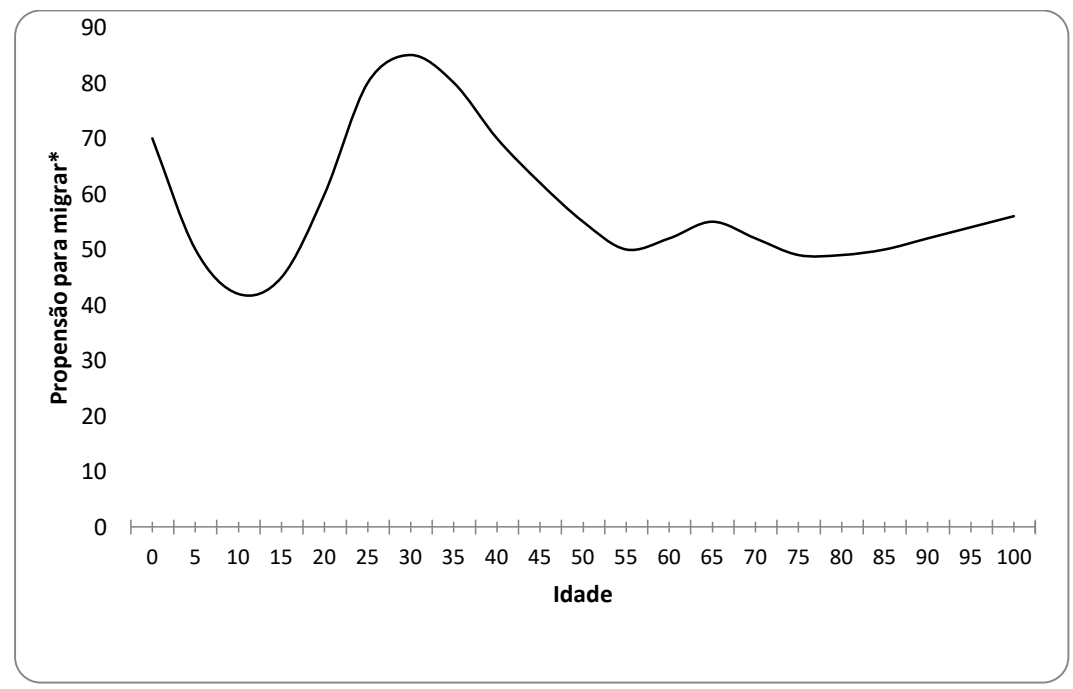

Fonte: desenho esquemático baseado em Rogers e Castro (1981).

* no modelo original é usada taxa de migração por idade.

Essas ideias aproximam-se das chamadas "teorias do ciclo de vida", que fazem referência aos papéis socialmente estabelecidos para indivíduos de cada idade (Glick, 1989), que discutem as variações do comportamento dos indivíduos à medida que a idade avança, ou das abordagens que se ocupam de estudar as trajetórias e transições que conformam as vidas individuais (Elder, 1985, 1994). Essas abordagens destacam a centralidade das transições na conformação da história individual, seja de sua relação com eventos que ocorrem em idades específicas, seja como resultado do momento que o indivíduo se encontra em sua trajetória no curso da vida, salientando a importância das análises de processos e não apenas dos atributos individuais em pontos fixos no tempo.

Tratando, de forma um pouco mais detalhada, dos principais aspectos relacionados à migração e idade, temos estudos voltados para a migração de crianças (Dobson, Sillwell, 2000; Dustmann, 2003) e a influência do avanço do processo educacional na decisão de migrar ou não. Entre aqueles dedicados aos estudos dos jovens e adultos, grupos populacionais que mais migram, podemos destacar, a perspectiva da Teoria do Capital Humano (Sjaastad, 1980; Borjas, 1996). Essa abordagem destaca que os ganhos com a migração declinam com o avanço da idade, a probabilidade migratória declina ao longo da vida produtiva (Borjas, 1996). Por fim, há vários estudos dedicados à migração de idosos (Biggar, 1980; Bures, 1997; Chen, Wilmoth, 2004; Choi, 1996; Campos, Barbieri, Guedes, 2012; Litwin, 1998; Litwak, 
Longino, 1987; Walters, 2002), que mostram, de diferentes maneiras, os impactos do envelhecimento nas alterações da probabilidade de migrar.

Com base nas ideias discutidas, vê-se a importância de considerar as transições experimentadas por indivíduos como tendo um papel primordial para a compreensão dos movimentos migratórios. Pelo fato das transições estarem inseridas em processos dinâmicos que ocorrem em níveis mais agregados, é necessário que sejam tratadas em conjunto com as transições que ocorrem nesses níveis, nas famílias e nos domicílios.

\section{Família e migração sob uma perspectiva cíclica}

Peter Rossi, um estudioso de destaque no estudo da mobilidade residencial, escreveu em 1988 que seu livro (Citation Classics Essays of an Information Science) "Why Families Move: a study in the social psychology of urban residential" publicado mais de 30 anos antes, em 1955, desafiara as visões predominantes da época sobre a mobilidade residencial, mostrando ser essa um processo de ajustamento das famílias a mudanças na composição domiciliar (ciclo de vida familiar), e não uma resposta aos atributos individuais dos membros da família. Sendo ou não o único estudo a contribuir para a mudança de perspectiva de análise para a mobilidade espacial da população, fato é que desde então diversos estudos sobre migração e mobilidade têm destacado a importância da família ou domicílio como unidade de análise privilegiada para a compreensão dos deslocamentos populacionais, embora poucos tenham se dedicado, como fez Rossi (1988), a estudar o papel do ciclo de vida do domicílio na migração.

Mesmo nas abordagens econômicas da migração, campo em que muitas vezes imperam as análises das características individuais como estímulos para a migração, surgiram nas últimas décadas correntes como a chamada Nova Economia da Migração do Trabalho (NEMT), em que a mobilidade espacial é vista, explicitamente, como uma das estratégias de caráter familiar ou domiciliar (Stark, Bloom, 1985; Stark, Taylor, 1991).

Um ponto importante para a compreensão da relação entre migração e família é o fato de que, em grande parte das vezes, os membros da família migram ou deixam de migrar devido à migração de outro morador. Nessa perspectiva Mincer (1978) classificou os indivíduos como "tied movers" ou "tied stayers", estando no primeiro grupo os indivíduos que individualmente não migrariam, mas são levados a migrar para acompanhar os familiares, enquanto no outro grupo, dos "tied stayers", estariam aqueles estimulados a migrar mas que não o fazem devido ao fato de que os ganhos com a migração não compensam os custos de mover dos outros membros da família.

Para o que nos interessa neste trabalho, de analisar as transições pelas quais as famílias passam, destaca-se o trabalho de Perz (2001), que estuda a 
mobilidade populacional em áreas de fronteira agrícola. Numa perspectiva de transição, o autor mostra que a propensão migratória de todos ou alguns dos membros do domicílio altera-se à medida que o tamanho e composição do domicílio varia ao longo do tempo. O ciclo de vida domiciliar seria assim entendido como a série de estágios (demográficos) pelos quais as famílias passam e que alteram a propensão migratória de seus membros. Tal ideia de ciclo de vida domiciliar foi inspirada nos trabalhos de Alexander Chayanov, que estudou o ciclo de vida domiciliar dos camponeses russos (Hammel, 2005), cuja abordagem foi ampliada por Hammel (2005) para domicílios complexos ou famílias estendidas.

Assim como no caso do ciclo de vida individual, a etapa em que o domicílio encontra-se no ciclo de vida influencia sua demanda por residência, dado seu tamanho e composição e, com isso, altera sua propensão migratória. As mudanças na família como, por exemplo, a saída dos filhos do domicílio, eliminam a necessidade de moradias maiores, podendo levar à mudança para outra residência (Wiseman, Roseman, 1979).

\section{Transição demográfica e migração: uma abordagem macroestrutural}

A chamada "transição demográfica" refere-se à passagem de um regime demográfico com altas taxas de mortalidade e fecundidade/natalidade para um regime em que ambas permanecem em níveis relativamente baixos. Esse processo tem sido observado recentemente em quase todas as populações do planeta, geralmente estando atribuído ao processo de modernização das sociedades. Embora seja possível observar comportamentos particularizados (idiossincráticos) de algumas populações quanto à velocidade da transição e valores de cada componente demográfica, a universalidade do processo ilustra o fato de que as populações, como um todo, também são passíveis de serem analisadas em termos de transições.

Primeiramente, é importante destacar que a transição demográfica se direciona principalmente para o estudo das mudanças no comportamento da fecundidade e mortalidade (Caldwell, 1976; Kirk, 1996; Lesthaeghe, 2010), negligenciando, em grande parte, o comportamento da migração. Essa variável normalmente é considerada como um fator exógeno que tanto pode condicionar a transição da mortalidade e fecundidade - como no caso da migração para as cidades que leva a novos comportamentos - ou como apenas um fator afetado por estas, como nos estudos que enfatizam a existência de uma "migração de reposição", necessária para recompor o contingente populacional - de jovens - "perdido" pelas sociedades que estão experimentando o envelhecimento acelerado de suas estruturas etárias (Leastaghe, 2010). 
A negligência em considerar uma componente demográfica no conceito de transição demográfica deixa espaço para o tipo de crítica feita por Zelinsky (1971), que opõe a "transição da mobilidade" ao que ele chama "transição vital", ou dos eventos vitais (biológicos) nascer e morrer. O autor sugere que a transição só seria de fato "demográfica" se incorporasse todas as componentes demográficas, ou seja, incluísse as alterações no padrão de mobilidade espacial da população como elementos centrais aos modelos explicativos.

$\mathrm{Na}$ tentativa de cobrir essa lacuna, Zelinsky (1971) realiza um tratamento das migrações sob uma perspectiva de transição. Segundo o autor, à medida que a sociedade se moderniza, há uma alteração na intensidade e na forma da mobilidade espacial em termos de volume e padrão espacial dos deslocamentos, entendidos como a frequência, duração, periodicidade, distância e categoria de migrantes (Zelinsky, 1971, p. 222).

$\mathrm{O}$ autor divide este processo em estágios pelos quais as sociedades passariam ao longo da transição. No primeiro estágio, em vigor nas sociedades tradicionais ou "pré-modernas", haveria pouca mobilidade dos indivíduos. No início do processo de modernização, representado pelo segundo estágio, seria observada uma migração intensa das áreas rurais para as cidades e para as regiões de fronteira econômica. Na terceira fase, que representa a consolidação da modernização, haveria uma diminuição da intensidade dos fluxos migratórios. O quarto estágio, que representa a sociedade moderna consolidada, caracterizar-se-ia pela alta mobilidade populacional, com migração predominante entre as áreas urbanas. A quinta fase, que o autor denomina de "sociedade futura" (pós-moderna), exibiria uma queda da migração, devido ao aumento das facilidades de comunicação e transporte. Ao mesmo tempo, surgiriam novas formas de mobilidade, com destaque para os movimentos intraurbanos.

Embora, em termos conceituais, as hipóteses de transição da mobilidade de Zelinsky sejam bastante atraentes, elas destacam-se mais por seu valor discursivo (como ideia) do que por sua fundamentação empírica. Não há como falar em uma regularidade e nem em uma generalidade na experimentação do processo de transição da mobilidade. De Haas (2008), ao abordar a relação entre migração e desenvolvimento, destaca que o fundamental no trabalho de Zelinsky é o fato de ele relacionar estágios específicos de migração e mobilidade ao processo geral de desenvolvimento socioeconômico e demográfico da população. O próprio Zelinsky afirmou que a originalidade do seu texto reside na aglutinação de ideias presentes na literatura de economistas e geógrafos sobre os ciclos migratórios experimentados ao longo do processo de modernização (Zelinsky, 1971, p. 221). Dessa forma estar-se-ia justamente enfatizando a "historicidade" das migrações e sua integração ao processo de desenvolvimento das sociedades. 
Sob uma perspectiva diferente, Skeldon (2012) discute as alterações nos padrões de mobilidade da população que, sustenta o autor, evoluiriam de uma mobilidade circular entre pequenas localidades que, ao longo do tempo, teria ampliando seu "raio de circulação", incorporando a migração para cidades médias e grandes. Embora o próprio autor situe seu trabalho em paralelo com o de Zelinsky, em essência, a transição que ele apresenta relaciona-se mais a alterações nos padrões de mobilidade entre cidades hierarquicamente relacionadas do que entre mudanças no comportamento dos migrantes.

Essa mudança de perspectiva conduz aos trabalhos que se concentram no resultado final dos fluxos populacionais, principalmente entre áreas urbanas, em estudos que destacam a intensidade e as características dos processos de urbanização. Essas abordagens, também destacam as transições que se observam nesses processos, compreendidas no conceito de "transição urbana". Esse processo, vale destacar, também é um dos principais atributos da modernidade, estando muitas vezes no cerne das explicações dos outros processos de transição. Afinal, o início do processo de modernização é representado, dentre outros aspectos, pela migração das populações rurais para as cidades.

Interessante notar que o processo de urbanização em si também costuma ser caracterizado por uma delimitação de fases ou etapas estilizadas. O trabalho de Champion (2001) apresenta diferentes etapas de concentração e desconcentração da população em áreas urbanas, descrevendo a urbanização intensa ocorrida na década de 1950 nos países centrais; a suburbanização observada na década de 1960; a contraurbanização vivida da década de 1970 e a reurbanização na década de 1980.

Embora o objeto em estudo (a cidade) não seja central para a presente análise, é interessante notar como a perspectiva de transição é esclarecedora quanto aos fenômenos experimentados pela sociedade e a interseção que ocorre entre arcabouços conceituais de diferentes corpos disciplinares, chegando ao ponto de alguns autores como Roberts (1991) falarem de "ciclos de vida das cidades". Segundo essa perspectiva, a cidade teria um período de juventude, com crescimento acelerado, passaria por um período de maturidade, com crescimento estável, até chegar a uma era de declínio populacional, que a caracterizaria como "cidade "madura" (Roberts, 1991).

\section{Integrando as diferentes abordagens}

Esta seção aponta alternativas para a integração das transições ocorridas nas escalas individual, domiciliar e populacional em sua relação com a migração. Embora essa tarefa possua uma complexidade significativa para ser resolvida no escopo deste trabalho, julga-se que as ideias apresentadas 
podem servir de base para avanços subsequentes na mesma direção. Fazemos a defesa de que os eventos sejam vistos em uma perspectiva processual, e não considerados como fatos sedimentados. Isso provocaria nossos estudos a estar continuamente buscando novas articulações dos fenômenos migratórios e interpretando nossos achados como "momentos" pelos quais passam os processos migratórios, e não como suas características essenciais. Assim são compreendidos de forma mais ampla se, no lugar de focarmos exclusivamente em atributos de indivíduos ou instituições sociais em que estão inseridos, direcionarmos nossa atenção para as transições por que passam os indivíduos, as famílias e as populações. Além disso, acreditamos que isso pode ser potencializado se conseguirmos integrar verticalmente, encadeando as transições que ocorrem em diferentes escalas.

Partindo de transições que foram descritas, cabe a nós avançarmos no sentido de articular algumas dessas ideias. Não se quer aqui, conforme já dito, resolver a questão agência estrutura, mas mostrar como uma análise processual é passível de ser realizada sem aumentar a tensão analítico-conceitual que ocorre ao se aproximar dos extremos macro ou micro da ação social.

O próximo desafio seria a identificação de elementos responsáveis pela articulação entre as escalas de análise, ou seja, focar no aspecto relacional que conecta as escalas que estariam, no plano conceitual, hierarquicamente organizadas conforme a relação

$$
\text { indivíduos < famílias < população }
$$

Como são categorias analíticas desmembradas para estudar o mesmo fenômeno (as migrações), na realidade elas já estão articuladas cabendo a nós descobrir a forma como isso ocorre.

Pode-se pensar, a título de exercício, que as transições ocorridas em diferentes níveis escalares articulam-se em duas direções: agregativas (de baixo para cima) e desagregativas (de cima para baixo). Avançando um pouco mais, pode-se considerar que essa articulação possui um caráter dialético, acontecendo simultaneamente nas duas direções.

De forma simplificada, toma-se como exemplo da relação agregativa observada em determinados tipos de padrão demográfico, as mudanças no comportamento individual quanto à nupcialidade e à decisão de ter filhos que afetam o padrão de formação de domicílios e, consequentemente, seu ciclo de vida ao longo do tempo. Ambos aspectos, em termos agregados, levam ao envelhecimento da estrutura etária da população e propiciam modificações nas relações intergeracionais, nas estruturas de suporte e de transferências de recursos. Essa nova configuração da estrutura da população sinaliza como estímulo para mudança ou manutenção do padrão de formação domiciliar e 
do comportamento quanto à nupcialidade e à reprodução, determinando a relação desagregativa que ocorre no sentido inverso.

A Figura 2 mostra essas ideias de forma esquemática, fazendo uma tentativa de "colocar em movimento articulado" os aspectos apresentados na Figura 1.

\section{Figura 2 - Articulação entre as transições e seus níveis escalares}

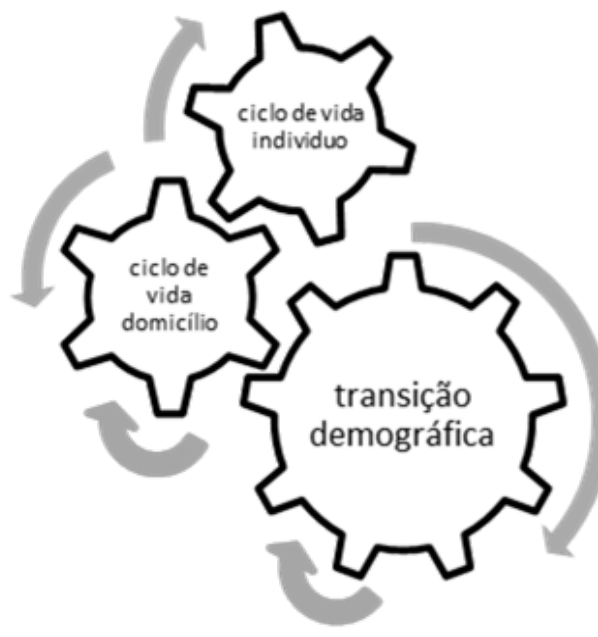

Fonte: elaboração própria

Em relação ao tema em discussão, as migrações, vimos que indivíduos que vivem sós têm uma propensão migratória diferente dos que estão em algum tipo de união; domicílios menores ou maiores apresentam possibilidades diferentes de levar alguns de seus membros à migração ou à fixação em determinado lugar; que a alocação de recursos na sociedade, como escolas, hospitais e redes de assistência social, também influencia nos padrões de distribuição espacial da população. Além disso, uma vez que a migração ocorre, ela gera transformações na vida do indivíduo, do domicílio e da população, que irão impactar nas decisões futuras de migração, num fenômeno chamado por Massey (1990) de "processo de causação cumulativa". Massey - que no trabalho citado também defende as análises multiescalares de migração, só que a partir de uma perspectiva longitudinal - afirma que uma vez ocorrida, a migração altera as características das sociedades envolvidas gerando alterações nos movimentos migratórios subsequentes. A interação dinâmica entre o crescimento da rede social de migração individual, as remessas financeiras e a redistribuição da renda entre os locais de origem e destino criam mecanismos que levariam a mais migração, num processo de causação cumulativa. 
No mesmo sentido, Davis (1963), ao propor uma teoria para mudança e resposta em demografia, destaca que o processo de mudança demográfica não é apenas contínuo, mas também reflexivo, dado que a mudança em uma componente demográfica, eventualmente, é alterada pela mudança em outra componente.

A chamada "migração de reposição", necessária para repor a falta de jovens no mercado de trabalho nas populações com estruturas etárias envelhecidas, é outro exemplo de articulação entre processos agregados (envelhecimento demográfico) e estratégias migratórias individuais e familiares, na escolha dos locais de destino. Do mesmo modo, o comportamento migratório de indivíduos mais velhos em uma população com estrutura etária envelhecida pode ser diferente do comportamento migratório de indivíduos com as mesmas idades em uma população demograficamente mais jovem, assim como o comportamento migratório dos jovens será condicionando por uma conjuntura demográfica relativamente mais envelhecida, dado que as estruturas de suporte (familiares ou sociais) afetam em grande medida a decisão da migração (Campos, 2012).

Um outro ponto que merece destaque é a importância que vem sendo dada ao domicílio como unidade privilegiada de análise da migração. Alguns autores creditam a essa unidade de análise o papel de fazer a conexão entre o indivíduo e a sociedade (Harbinson, 1981). Dentre outros aspectos, isso decorre da facilidade de articulação entre níveis individuais e questões estruturais que a análise domiciliar propicia. Traz-se a estrutura para uma escala mais próxima dos indivíduos, reduzindo a distância entre essas esferas. Esse é avanço proposto pela Nova Economia da Migração do Trabalho, por exemplo (Stark, Bloom, 1985), que segundo De Haas (2008) é uma estratégia para rearticular agência e estrutura nas análises de migração e, a nosso ver, articular processos que ocorrem em diferentes escalas.

O privilégio analiticamente dado a uma unidade de análise é um artifício metodológico que, ao longo do tempo, fez com que perdêssemos a visão abrangente dos processos migratórios que sofre influência da interação de processo que aparentam ocorrer em diferentes escalas.

\section{Considerações finais}

Análises feitas com base em categorias estanques não são favoráveis para o entendimento de cenários de mudança, principalmente em relação a processos sociais dinâmicos como a migração. Este trabalho busca apresentar um arcabouço conceitual multiescalar de transição das migrações. O arcabouço desenvolvido relaciona a migração com as transições ocorridas ao longo do ciclo de vida individual, domiciliar e, em termos agregados, o processo de 
transição demográfica da população. Embora não se tenha buscado criar novas teorias, o presente trabalho promove articulação de posições teóricas complementares, muitas vezes tratadas em separado, permitindo verificar lacunas explicativas e, consequentemente, favorecendo o desenvolvimento de teorias futuras. O esforço insere-se na busca - ocorrida em diversos ramos das ciências sociais e, não por acaso, também entre os estudos recentes da migração - de uma articulação entre teorias que dão predominância a aspectos situados em diferentes escalas para explicar a ocorrência dos fatos sociais.

Contudo, diferentemente das revisões teóricas sobre migração que afirmam que a fragmentação dos corpos teóricos leva a um distanciamento no entendimento da migração (Brettell, Hollifield, 2000; Massey et alii, 1998), acredita-se ser possível acumular conhecimento sobre a realidade a partir do estudo de aspectos particulares desta mesma realidade. Nesse sentido, ao invés de uma insuficiência ou crise teórica, acredita-se que, se houver desequilíbrio em alguma direção, essa seria de profusão de teorias sobre migração. Apesar de ser possível acumular conhecimento a partir de pontos de vista diferentes e em competição, a unilateralidade destes discursos acabou tornando impossível sua sustentação. Contudo, conforme destacado, a fragmentação das unidades de decisão da migração é muito mais um constructo metodológico do que uma característica do fenômeno em si. Conforme defende Alexander (1987), ao invés de considerar o desacordo como um problema das teorias de migração, toma-se o conflito entre escolas como indicador saudável do caráter da disciplina. Não se quer, contudo, adotar uma "perspectiva pós-moderna" de completo relativismo em que tudo poderia estar explicando tudo. O que se quer é chamar atenção para o fato de que as ideias já estão aí e de que não é precisamos recriá-las.

Processo dinâmicos presentes em diferentes escalas imbricam-se continuamente para determinar a ocorrência da migração. Esse é o fenômeno que se buscou destacar: ao invés de articular as escalas, pretende-se mostrar que elas sempre fizeram parte de um mesmo processo, que se altera continuamente com implicações para indivíduos, famílias e populações. A migração seria uma resposta do indivíduo a uma determinada conjuntura a ele e a seus familiares apresentada pela sociedade, também intermediada pela família. Como todas essas esferas estão em constante transformação, a migração precisa ser vista também por uma lente dinâmica, uma lente multifocal, que abarque todos os níveis e suas transformações.

Embora Alexander (1987) insista que a teorização num nível geral constitui um esforço significativo e crucial das ciências sociais, acredita-se mais na articulação entre teorias opostas do que na construção de um consenso teórico absoluto. Sem estas perguntas, dificilmente teremos respostas para problemas comuns no entendimento da migração, como o impacto da 
"evolução" dos meios de transporte e comunicação na reconfiguração da rede social do migrante ou como o aumento da longevidade e o aumento do período de dependência podem reconfigurar o perfil migratório de toda a sociedade.

Estudos desta natureza, embora carreguem elevada carga conceitual e um nível de abstração que torna difícil a empirização das ideias, ajudam a clarificar a natureza dinâmica e multiescalar dos fenômenos sociais. Considera-se, contudo, a importância de avanços continuados na tentativa de orientar análises empíricas dos processos migratórios na perspectiva aqui apresentada.

\section{Referências bibliográficas}

ALEXANDER, Jeffrey. Novo movimento teórico. Revista Brasileira de Ciências Sociais, n. 4, v. 2, p. 5-28,1987.

BIGGAR, Jeanne. Who moves among the elderly, 1965-70: a comparison of types of older movers. Research on Ageing, v. 2, n. 1, p. 73-91, 1980.

BORJAS, Geoge. Labor Economics. New York: Mac Graw Hill, 1996.

BRETTELL, Caroline; HOLLIFIELD, James Frank. Migration theory: talking across disciplines. New York; London: Routledge, 2000.

BURES, Regina. Migration and the life course: Is there a retirement transition? International Journal of Population Geography, Chichester, v. 3, n. 2, p. 109-119, 1997.

BURT, Ronald. Brokerage and Closure: an introduction to social capital. New York: Oxford University Press, 2005.

CALDWELL, John. Towards a restatement of demographic theory. Population and Development Review, v. 2, n. 3/4, p. 321-366, 1976.

CAMPOS, Marden B. Reversão do saldo migratório internacional negativo do Brasil? Evidências preliminares com base nos dados do Censo 2010. Informe GEPEC (Online), v. 15, p. 387-397, 2012.

CAMPOS, Marden; BARBIERI, Alisson F.; GUEDES, Gilvan. Transición de la movilidad: Estudio de perfiles de migrantes de la tercera edad en el Brasil. Notas de Poblacion, n. 94, 2012.

CASTRO, Luis; ROGERS, Andrei. What the age composition of migrants can tell us. Population Bulletin of the United Nations, New York, n. 15, p. 63-79, 1983.

CHAMPION, Tony. Urbanization, Suburbanization, Counterurbanization and Reurbanization. In: PADISON, Ronan (ed.). Handbook of Urban Studies. London: SAGE Publication, 2001.

CHEN, Pei-Chun; WILMOTH, Janet. The effects of residential mobility on ADL and IADL limitations among the very old living in the community. Journal of Gerontology: Social Sciences, v. 59b, n. 3, p. 164-172, 2004.

$\mathrm{CHOI}$, Namkee. Older persons who move: reasons and health consequences. Journal of Applied Gerontology, v. 15, n. 325, p. 325-344, 1996. 
DAVIS, Kinsley. The theory of change and response in modern demographic history. Population index, v. 29, n. 4, p. 345-366, 1963.

DE HAAS, Hein. Migration and development: a theoretical perspective. Working Paper n. 9. Oxford: International Migration Institute, 2008.

DE JONG, Gordon; GARDNER, Robert (eds.). Migration decision making: multidisciplinary approaches to microlevel studies in developed and developing countries. New York: Pergamon Press, 1981.

DOBSON, Janet; STILLWELLF, John. Changing home, changing school: towards a research agenda on child migration. Area, v. 32, n. 4, p. 395-401, 2000.

DUSTMANN, Christian. Children and return migration. Journal of Population Economics, v. 16, p. 815-30, 2003.

ELDER Jr., Glen. Perspectives on the life course. In: ELDER Jr., Glen (ed.). Life course dynamics: trajectories and transitions, 1968-1980. New York; London: Cornell University Press, 1985.

ELDER Jr., Glen. Time, human agency, and social change: perspectives on the life course. Social Psychology Quarterly, v. 57, n. 1, p. 4-15, 1994.

GIDDENS, Anthony; TURNER, Jonathan. Teoria Social Hoje. São Paulo: UNESP, 1999.

GLICK, Paul. The life cycle and social change. Family Relations, v. 38, n. 2, p. 123129, 1989.

HAMMEL, Eugene. Chayanov revisited: a model for the economics of complex kin units. PNAS, v. 102, n. 19, p. 7043-7046, 2005.

HARBINSON, Sarah. Family structure and family strategy in migration decision making. In: DE JONG, Gordon; GARDNER, Robert (eds.). Migration decision making: multidisciplinary approaches to microlevel studies in developed and developing countries. New York: Pergamon Press, 1981.

KIRK, Douglas. Demographic transition theory. Population Studies, v. 50, p. 361387, 1996.

LEE, Everett. Uma teoria sobre a migração. In: MOURA, Helio A. (org.). Migração interna, textos selecionados: teorias e métodos de análise. Fortaleza: BNB, t. 1, p. 89-114, 1980.

LESTHAEGHE, Ron. The Unfolding Story of the Second Demographic Transition. PSC Research Report, n. 10-696, 2010.

LITWAK, Eugene; LONGINO, Charles. Migration patterns among the elderly: a development perspective. The gerontologist, v. 27, n. 3, p. 266-272, 1987.

LITWIN, Howard. Social network type and health status in a national sample of elderly Israelis. Social Science and Medicine, v. 46, n. 4/5, p. 599-609, 1998.

MASSEY, Douglas S.; ARANGO, Joaquin; HUGO, Graeme; KOUAOUCI, Ali; PELLEGRINO, Adela; TAYLOR, Edward. Worlds in motion: understanding international migration at the end of the millennium. Oxford: Clarendon Press, 1998. 
MASSEY, Douglas. Social structure, household strategies and the cumulative causation of migration. Population Index, Princeton, v. 56, n. 1, p. 3-26, 1990.

MINCER, Jacob. Family Migration Decisions. The Journal of Political Economy, Chicago, v. 86, n. 5, p. 749-773, 1978.

PERZ, Stephen. Household demographic factors as life cycle determinants of land use in the Amazon. Population Research and Policy Review, v. 20, n. 3, p. 159186, 2001.

ROBERTS, Susan. A critical evaluation of the city life cycle idea. Urban Geography, v. 12, n. 5, p. 431-449, 1991.

ROGERS, Andrei; CASTRO, Luis. Model migration schedules. Luxemburg: International Institute for Applied Systems Analysis, 1981.

ROSSI, Peter. This Week's Citation Classic. Essays of an Information Science, n. 1, 1988.

SANTOS, Milton. A Natureza do Espaço: espaço e tempo, razão e emoção. São Paulo: Hucitec, 1998.

SJAASTAD, Larry. Os custos e os retornos da migração. In: MOURA, Helio (org.). Migração interna, textos selecionados: teorias e métodos de análise. Fortaleza: BNB, 1980.

SKELDON, Ronald. Migration transitions revisited: their continued relevance for the development of migration theory. Population Space and Place, v. 18, n. 2, p. 154-166, 2012.

STARK, Oded; BLOOM, David. The new economics of labor migration. AEA Papers and Proceedings: frontiers in demographic economics, v. 75, n. 2, p. 173-178, 1985.

STARK, Oded; TAYLOR, J. Edward. Migration incentives, migration types: the role of relative deprivation. The Economic Journal, v. 101, n. 408, p. 1163-1178, 1991.

WALTERS, Willian. Later-life migration in the United States: a review of recent research. Journal of Planning Literature, [s.I], v. 17, n. 2, p. 37-66, 2002.

WISEMAN, Robert; ROSEMAN, Curtis. A typology of elderly migration based on the decision-making process. Economic Geography, v. 55, n. 4, p. 324-337, 1979.

ZELINSKY, Wilbur. The Hipothesis of the Mobility Transition. Geographical Review, v. 61, n. 2, 1971. 